\title{
MicroRNA-30a-5p Inhibits the Growth of Renal Cell Carcinoma by Modulating GRP78 Expression
}

\author{
Changlin Wang ${ }^{a}$ Licheng Cai ${ }^{a}$ Jing Liu ${ }^{a}$ Gang Wang ${ }^{a}$ Haoming Lia \\ Xiaoxiong Wang ${ }^{b}$ Wanhai Xu ${ }^{c}$ Minghua Ren ${ }^{a}$ Li Feng $^{d}$ Pinghuang Liud \\ Cheng Zhang ${ }^{\text {a }}$
}

aDepartment of Urology, The First Affiliated Hospital of Harbin Medical University, Harbin, bDepartment of Neurosurgery, The First Affiliated Hospital of Harbin Medical University, Harbin, 'Department of Urology, The Fourth Affiliated Hospital of Harbin Medical University, Harbin, 'State Key Laboratory of Veterinary Biotechnology, Harbin Veterinary Research Institute, Chinese Academy of Agricultural Sciences, Harbin, China

\section{Key Words}

MicroRNA-30a-5p • Renal cell carcinoma $•$ GRP78 • ER stress

\begin{abstract}
Background/Aims: MiR-30a-5p, a member of the microRNA-30 family (miR-30), is known to function as a tumor suppressor in several different cancers. However, the expression levels, biological function, and underlying mechanisms of miR-30a-5p in renal cell carcinoma (RCC) remain unclear. Glucose-regulated protein78 (GRP78) is a common cancer biomarker and promotes the growth and survival of cancer cells. The expression of GRP78 has been reported to be modulated by miR-30a in neurons. In this study, the expression profile of miR$30 a-5 p$ in clear cell renal cell carcinoma (ccRCC) and its effect on ccRCC through regulating GRP78 expression was investigated. Methods: MiR-30a-5p expression was analyzed using bioinformatic software on open microarray datasets from the Cancer Genome Atlas (TCGA) and Gene Expression Omnibus (GEO), and confirmed by quantitative RT-PCR (qRT-PCR) in cCRCC cell lines. Cell proliferation was investigated using CCK-8 and cell count assays. Western blotting, immunohistochemistry, luciferase reporter assays, and flow cytometry were employed to investigate the mechanisms of the effect of miR-30a-5p on ccRCC. Results: MiR-30a-5p was down-regulated in ccRCC and related to the clinicopathological factors and prognosis of ccRCC. MiR-30a-5p was found to both suppress the growth of ccRCC cells and promote apoptosis of ccRCC cells in vitro. GRP78 was the direct target gene of miR-30a-5p, and the GRP78 expression was inversely correlated with the expression of miR-30a-5p in vivo and in vitro. The functional studies of GRP78 overexpression or knockdown demonstrated that GRP78 promoted proliferation and anti-apoptosis of ccRCC cells, and the oncogenic activity of GRP78 resulting in by miR-30a-5p overexpression. Conclusion: MiR-30a-5p is a bona fide negative regulator of GRP78 expression, and the anti-tumor activity of miR-30a-5p in ccRCC is due at least in part to down-regulating GRP78 expression and modulating the unfolded protein response (UPR) pathway. Thus, miR-30-GRP78 interaction provides a novel therapeutic candidate target in cCRCC treatment.




\section{Cellular Physiology Cell Physiol Biochem 2017;43:2405-2419 and BiOChemistry Published online: October 27, 2017 \begin{tabular}{l|l} 
DOI: 10.1159/000484394 2017 The Author(s). Published by S. Karger AG, Basel \\
www.karger.com/cpb
\end{tabular} \\ Wang et al.: MicroRNA-30a-5p Inhibits the Growth of Renal Cell Carcinoma}

\section{Introduction}

Renal cell carcinoma (RCC) is a common urologic malignancy and accounts for $\sim 3 \%$ of adult malignancies and causes $\sim 900,00$ deaths worldwide annually [1]. RCC encompasses the cancer subtypes of clear cell, papillary, and chromophobe subtypes, which have distinct structural and cytogenetic characteristics $[2,3]$. The most common RCC subtype is clear cell RCC (ccRCC), which accounts for $80 \%$ of RCC cases. Apart from surgery, RCC is relatively radiotherapy, chemotherapy resistant and targeted therapy [4, 5]. Early detection is critical for patient outcome, the 5 -year survival rate for patients diagnosed with organ-confined disease is approximately 93\% [6], whereas the prognosis of patients with distant metastasis remains poor with a 5 -year survival of less than 10\% [7]. However, at present biomarkers for early detection and follow-up of RCC are not available, resulting in late diagnosis and subsequent poor prognosis. Therefore, searching for novel tumor biomarkers for patients with RCC and novel anti-RCC treatment has become a focus of basic and clinical RCC research.

MicroRNAs (miRNAs) are a class of evolutionarily conserved; approximately 22 nucleotides long, non-coding, single stranded endogenous RNA molecules. MiRNAs modulate the expression of target genes by binding to the complementary seed sequences in the 3'UTRs of mRNAs and act as key post-transcriptional regulators of target mRNAs [8]. The mature miRNA is incorporated into the RNA-induced silencing complex (RISC) and drives the selection of target mRNAs containing antisense sequences, thus controlling target gene expression [9]. Growing evidence demonstrates that miRNAs play a critical role in cancer progression [10]. Recent evidence proposed miRNAs as promising biomarkers for early cancer detection and accurate prognosis as well as targets for cancer treatment. Recently, growing evidence has demonstrated miRNA dysregulation in ccRCC; the expression levels of miRNAs are related with disease severity and survival of RCC patients. For example, high $\mathrm{miR} 21 / 10 \mathrm{~b}$ is associated with poor prognosis [11]. Up-regulation of oncogenic TAGLN2 is due to down-regulation of tumor-suppressive miR-1 and miR-133a in human RCC [12]. The miR-30 members of the family (miR-30a, miR-30b, miR-30c-1, miR-30c-2, miR-30d and miR-30e) prominently expressed in kidney though expression in various tissues, and act as essential regulators in different cancers. For example, miR-30a suppresses settlement of invasion and metastasis of colorectal cancer cells by down-regulating PIK3D expression [13]; miR-30b targeting KRAS, PIK3CD and BCL2, prevents colorectal cancer development[ 14]; miR-30c can effectively inhibit lung cancer cell proliferation and reduce the potential for metastatic lung cancer cells [15]. Given the fact that the miR-30 is highly expressed in kidney, it is reasonable to expect that miR-30 family members are involved in the RCC progression. Previous study shows that miR-30d promotes the apoptosis of renal cell carcinoma by modulating the FOXO/Akt pathway [16]. Although miR-30a-5p is involved in several types of cancers, including breast, liver, glioma, colon, and thyroid cancer, the expression and role of miR-30a-5p in ccRCC progression remains unclear [17-21].

The endoplasmic reticulum (ER) is a multifunctional organelle and is responsible for protein translocation, protein folding, and protein post-translational modifications. Neoplastic, unlimited growth requires continuous synthesis of a great number of proteins. The unfold protein responses (UPR) are triggered to release the high burden of proteins processed through the ER and has been shown to play an important cytoprotective role that assists folding of newly synthesized proteins necessary for tumor growth. GRP78, an ER chaperone, has been well established as a marker for ER stress and is also considered to be a master regulator of the UPR. GRP78 is overexpressed in almost all the cancers and plays an important role in anti-apoptotic process of cancer cells [22]. Previous studies have demonstrated that GRP78 expression positively correlates with an increase of tumor progression, tumor size and poor outcome for patients with melanoma. The high levels of GRP78 expression are related to the large tumor size, aggressiveness, high clinical stage, resistance to conventional chemotherapy of RCC [23-25]. All these indicates that GRP78 plays a critical role in RCC and appears to be an interesting alternative target in cancer treatment. Previous studies have shown that miR-30 modulates the expression of GRP78 $[26,27]$. 


\section{Cellular Physiology Cell Physiol Biochem 2017;43:2405-2419

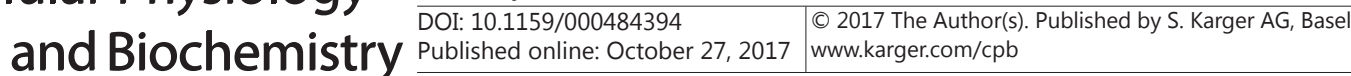 \\ Wang et al.: MicroRNA-30a-5p Inhibits the Growth of Renal Cell Carcinoma}

However, whether the dysregulation of miR-30 expression in RCC affects the progression of RCC through modulating GRP78 expression is still unknown.

In this study, the down-regulated expression of miR-30a-5p was identified from Gene Expression Omnibus (GEO) and was validated subsequently by ccRCC samples and Cancer Genome Atlas (TCGA) data. MiR-30a-5pwas correlated with clinicopathological factors and found to both inhibit the proliferation of ccRCC cells and enhance the apoptosis of ccRCC cells. Furthermore, we further demonstrated that the suppressive effect of miR-30a-5pon ccRCC was mediated by directly targeting GRP78 and down-regulating GRP78 expression. Our data show that miR-30a-5pmay play vital roles in renal cell cancer and provide a potential target for the treatment of renal cell carcinoma.

\section{Materials and Methods}

Patients and samples

In this study, ccRCC tissue and adjacent normal tissue specimens were collected from patients who were diagnosed histopathologically with ccRCC and received radical nephrectomy in the First Affiliated Hospital of Harbin Medical University. All ccRCC cases were confirmed by a senior pathologist, and staged based on the 2011 Union for International Cancer Control TNM classification of malignant tumors. The pathological diagnoses of all enrolled patients were confirmed by two blinded different pathologists, according to the WHO grading system. The study was approved by the Institutional Review Board of the First Affiliated Hospital of Harbin Medical University, and written informed consent was obtained from all patients.

Access and probe of online cancer datasets

The RNA-seq data of 249 tumor and 71 matched normal samples were downloaded from TCGA Data Portal (https://tcga-data.nci.nih.gov/tcga/). The expression of miRNAs was quantified by the customized data analysis pipeline that included the steps of quality control, alignment, and expression quantification. MiRNA array expression profile data GSE71302, were downloaded from GEO database (https://www.ncbi. nlm.nih.gov/geo/). Total RNA was extracted from 4 ccRCC tissues and paired adjacent normal specimens, and expression profiles of miRNAs were screened by using a miRNA microarray platform.

RNA extraction and quantitative real-time PCR

Total RNA was extracted from fresh samples preserved and frozen in liquid nitrogen using TRIzol Reagent (Invitrogen, Carlsbad, CA, USA) according to the manufacturer's instructions. Total RNA (1 $\mu \mathrm{g})$ was

Table 1. Real-time qRT-PCR primers used for quantification of renal cancer cell gene expression

\begin{tabular}{|c|c|c|}
\hline Gene name & & primer sequences $\left(5^{\prime}-3^{\prime}\right)$ \\
\hline \multicolumn{3}{|l|}{ qPCR primers } \\
\hline \multirow[t]{2}{*}{ GRP78 } & Forward & CGTCCTATGTCGCCTTCACT \\
\hline & Reverse & AATGTCTTTGTTTGCCCACC \\
\hline \multirow[t]{2}{*}{ GAPDH } & Forward & CATGTTCGTCATGGGTGTGAA \\
\hline & Reverse & GGCATGGACTGTGGTCATGAG \\
\hline \multirow[t]{3}{*}{ hsa-miR-30a-5p } & Forward & CGCGATGTGTAAACATCCTCGAC \\
\hline & Reverse & ATCCAGTGCAGGGTCCGAGG \\
\hline & $\begin{array}{c}\text { RT } \\
\text { primer }\end{array}$ & GTCGTATCCAGTGCAGGGTCCGAGGTATTCGCACTGGATACGACCTTCCA \\
\hline $\begin{array}{l}\text { hsa-miR-30a-5p } \\
\text { inhibitor }\end{array}$ & & CUUCCAGUCGAGGAUGUUUACA \\
\hline hsa-miR-30a-5p mimics & & UGUAAACAUCCUCGACUGGAAG \\
\hline GRP78 siRNA-1 & & GGUGGGCAAACAAAGACACAUTTAUGUCUUUGUUUGCCСАССТT \\
\hline GRP78 siRNA-2 & & GGUACUGCUUGAUGUAUGUTTACAUACAUCAAGCAGUACCTT \\
\hline
\end{tabular}




\section{Cellular Physiology Cell Physiol Biochem 2017;43:2405-2419

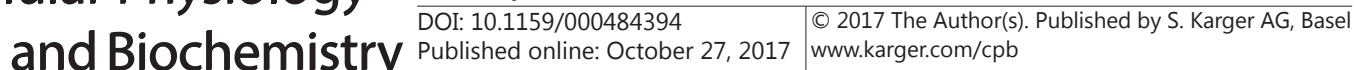 \\ Wang et al.: MicroRNA-30a-5p Inhibits the Growth of Renal Cell Carcinoma}

reverse transcribed into cDNA using High-Capacity cDNA Reverse Transcriptase Kits (TOYOBO, JAPAN). The relative level of miR-30a-5p to the control gene U6 was determined by qRT-PCR using a lightcycler-480 (Roche). PCR amplification was performed in triplicate, first at $95^{\circ} \mathrm{C}$ for $10 \mathrm{~m}, 40$ cycles of $95^{\circ} \mathrm{C}$ for $15 \mathrm{~s}$, and $60^{\circ} \mathrm{C}$ for $60 \mathrm{~s}$. The relative expression levels of miR-30a-5p were normalized to U6. The changes in the threshold cycle (CT) values were calculated by the equation $\Delta \mathrm{CT}=\mathrm{CT}$ (target) - CT (endogenous control) and fold difference was calculated as $2-\Delta(\Delta \mathrm{CT})$ and $-\Delta \mathrm{CT}$. Primers were designed using Oligo 6 software and are shown in Table 1.

\section{Prediction of miRNAs targeting GRP78}

The miRNA target predicting algorithms TargetScan Release 7.1 (http://www.targetscan.org/vert_71/), starBase v2.0 (http://starbase.sysu.edu.cn/) were used to predict miRNAs targeting GRP78 and their binding regions.

\section{Cell culture and transfection}

The human RCC cell lines 786-0, 769-P, OS-RC-1, OS-RC-2, Caki-1, ACNH, and Caki- 2 were obtained from the Shanghai Institutes for Biological Sciences. The cell lines 786-o, 769-p, OS-RC-1, OS-RC-2, Caki-1, and Caki-2 were cultured in RPMI 1640 (Gibco, Carlsbad, California). ACNH cells were maintained in DMEM (Gibco, Carlsbad, California) medium. Cells were cultured and supplemented with $10 \%$ fetal bovine serum (FBS) in a humidified atmosphere of $5 \% \mathrm{CO} 2$ maintained at $37^{\circ} \mathrm{C}$. Four synthetic, chemically modified short single or double stranded RNA oligonucleotides (miR-30a-5p mimics, mimics NC, miR-30a-5p inhibitor, inhibitor NC) were synthesized by Genepharma Biotech (Shanghai, China). $2 \times 10^{5}$ cells were plated in 6-well plates and transfected with $160 \mathrm{nmol} / \mathrm{L}$ miRNAs employing Lipofectamine ${ }^{\mathrm{TM}} 2000$ (Invitrogen) according to the manufacturer's protocol. The coding sequences GRP78 were amplified by PCR and inserted into pcDNA3.1 vector to generate GRP78 overexpression vectors.

\section{Cell proliferation assay}

A cell proliferation assay was carried out using the Cell Counting Kit-8 according to the manufacturer's instructions (Beyotime, Shanghai, China). Briefly, $3 \times 10^{3}$ cells were seeded in a 96 -well plate. Cell proliferation was assessed for 24, 48, and $72 \mathrm{~h}$. After adding $10 \mu \mathrm{lWST}-1$ reagents per well, cultures were incubated for 2 $\mathrm{h}$ and the absorbance was measured at $450 \mathrm{~nm}$ using a microplate reader (BioTek, VT, United States).

\section{Colony formation assay}

For the colony formation assay, 500 cells per well were seeded in 6-well plates. Visible colonies were observed using the naked eye at 10 days later, fixed with $4 \%$ formaldehyde, and stained with $0.1 \%$ crystal violet. Colonies with a diameter greater than $1 \mathrm{~mm}$ were counted.

\section{Flow cytometry}

The Annexin V-PE Apoptosis detection kit (BD Biosciences, San Jose, CA) was used to examine cell apoptosis according to the manufacturer's instructions. Briefly, cells were washed and resuspended in $1 \times$ Binding Buffer. Then, $100 \mu \mathrm{l}$ of the cell solution $\left(1 \times 10^{5}\right.$ cells $)$ was mixed with $5 \mu \mathrm{l}$ of Annexin V-PE and 5 $\mu \mathrm{l}$ of 7-AAD, and incubated for $15 \mathrm{~min}$ at room temperature. Then, $400 \mu \mathrm{l}$ of $1 \times$ binding buffer was added to each tube, and apoptosis analysis was performed in a FACScan instrument (Becton Dickinson, Mountain View, CA, USA).

\section{Luciferase activity assay}

The wild-type GRP78-3'UTR (WT) and mutant GRP78-3'UTR (MUT) containing the putative binding site of miR-30a-5p were chemically synthesized and cloned into the downstream of the firefly luciferase gene in a pGL3-promoter vector (Ambion). 293T cells were placed on a 48-well plate and grew until 80\% confluence. Cells were then co-transfected with luciferase plasmids and miR-30a-5p or control miRNA. After $48 \mathrm{~h}$ transfection, firefly and renilla luciferase activities were measured with a Dual-Luciferase Reporter Assay System (Promega).

\section{Western blotting}

Proteins were extracted from RCC cell lines using urea buffer (2 M Thiourea, 4\% CHAPS, 40mM TrisBase, 40mM DTT, 2\% Pharmalyte). Equal amounts of proteins were separated at sodium dodecyl sulfate- 


\section{Cellular Physiology Cell Physiol Biochem 2017;43:2405-2419

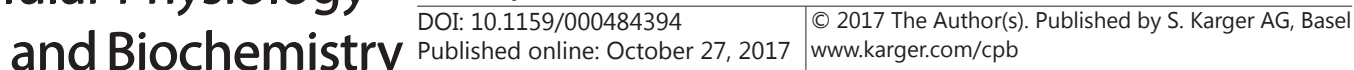 \\ Wang et al.: MicroRNA-30a-5p Inhibits the Growth of Renal Cell Carcinoma}

polyacrylamide gel electrophoresis (SDS-PAGE), and then transferred to PVDF membranes using cold transfer buffer. Membranes were blocked with $5 \%$ non-fat milk in TBS-T for $1 \mathrm{~h}$ at room temperature (RT), and subjected to corresponding primary antibody at $4^{\circ}$ Cover night. Antibodies used are listed as below: $\beta$-actin (Sigma-Aldrich, 1:8000), GRP78 (Sigma-Aldrich, 1:300). Secondary antibodies goat anti-mouse-HRP and goat anti-rabbit-HRP were diluted at 1:2000.

\section{Immunohistochemistry}

A tissue microarrays from 86 ccRCCs and 10 normal tissues were subjected to antigen retrieval by boiling in $0.01 \mathrm{~mol} / \mathrm{L}$ citrate buffer for $5 \mathrm{~min}$. Slides were then incubated with the predicted primary antibody at room temperature for $1 \mathrm{~h}$. Detection occurred by the REAL EnVision detection system (Dako) with diaminobenzidine peroxidase serving as a chromogen. The slides were briefly counterstained with hematoxylin and mounted. Staining was captured under the same conditions and its intensity was evaluated with a 3-tier grading system (negative or weak, moderate and strong staining intensity).

\section{Statistical analysis}

Clinical and pathologic associations between miR-30a-5p and GRP78 were determined using the chi-square test. The Kaplan-Meier method and log-rank test were performed to show survival differences according to miR-30a-5p and GRP78 expression, respectively. The time for overall survival was calculated as the time from surgery until the occurrence of death. Survival data were evaluated using univariate and multivariate Cox proportional hazards model. Variables with a value of $\mathrm{P}<0.05$ in univariate analysis were used in subsequent multivariate analysis on the basis of Cox regression analyses. The differences between groups in our in vitro experiments were analyzed using Student's t-test. Spearman correlation coefficients were calculated for correlation analysis. The correlation between miR-30a-5p levels and GRP78 protein expression was calculated by Spearman's correlation. A $\mathrm{P}<0.05$ was considered statistically significant. All experiments were performed in triplicate, and the SPSS 18.0 software system (SPSS, Chicago, IL) was used for statistical analysis. All statistical tests were two-sided, and $\mathrm{P}<0.05$ was considered statistically significant.

\section{Results}

\section{MiR-30a-5pexpression is decreased in ccRCC tissues and cells}

To explore the expression of miRNA profiles in ccRCCs, first, the GSE71302 dataset from GEO (https://www.ncbi.nlm.nih.gov/geo/) was used to analyze miRNA expression profiles in ccRCCs and matched normal tissues. A fold change greater than 2 and a $\mathrm{P}<0.05$ between tumor tissues and adjacent normal tissues were set as the criteria in filtering differently expressed miRNAs. The results of unsupervised hierarchical clustering analysis on 8 significantly dysregulated miRNAs ( $>2$-fold differences) are shown in Fig. 1A; 3 out of 8 dysregulated miRNAs (miR-34b-5p, miR-15a, and miR-30a-5p) were significantly down-regulated in ccRCCs (Fig. 1A). The down-regulated miRNA miR-30a-5p has been demonstrated to suppress other tumors and was further analyzed in our study. Next, TCGA data revealed that miR-30a-5p was significantly repressed in ccRCCs $(n=249)$ when compared with normal tissue samples ( $\mathrm{n}=71$; Fig. $1 \mathrm{~B}$ ). Then, the expression levels of miR-30a-5p in 50 pairs of human primary ccRCC and adjacent normal tissues in patents from the First Affiliated Hospital of Harbin Medical University were analyzed by qRT-PCR. Consistent with the data of GSE71302 and TCGA, miR-30a-5pexpression in ccRCC tissues was substantially reduced compared to the pair-matched adjacent normal tissues $(\mathrm{P}<0.001$, Fig. 1C). A decreased expression of miR-30a-5p was also observed in 5 different RCC cell lines (786-0, OS-RC-1, OS-RC-2, ACHN and Caki-2) compared to a normal kidney cell line (HK-2, human kidney-2) (Fig. 1D). Collectively, all the results indicate that miR-30a-5p is down-regulated in ccRCC.

Down-regulation of miR-30a-5p is associated with cCRCC TNM stages and poor prognosis Growing evidence demonstrates that miR-30a-5p can suppress tumor cell growth in breast cancer and colorectal cancer $[28,29]$. The decreased expression of miR-30a-5p was 
A

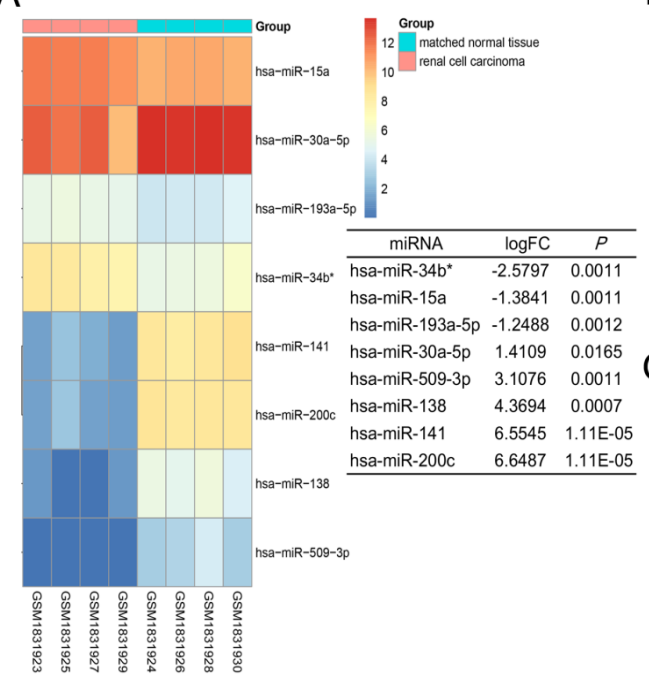

D

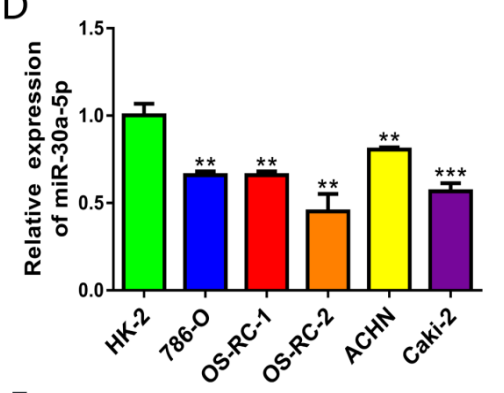

F

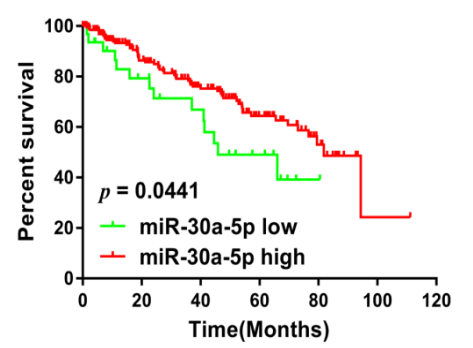

$\mathrm{B}$

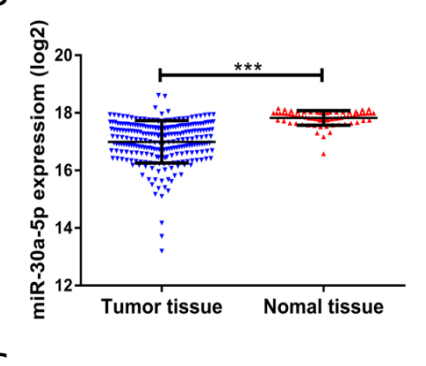

C

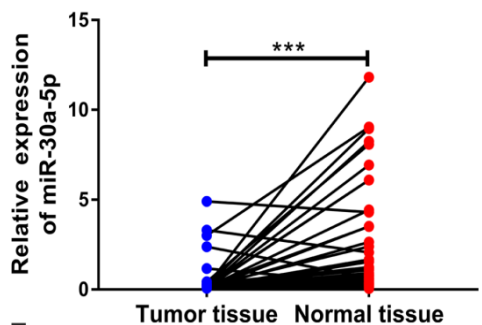

E

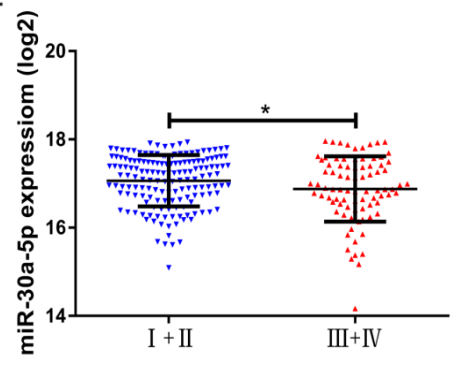

Fig. 1. Relative miR-30a-5p expression in ccRCC tissues and cell lines and its relationship with overall survival of ccRCC patients. (A) Heatmap showing miRNAs that are differentially expressed at least 2 -fold in either renal cell carcinoma $(n=4)$ versus matched normal tissue $(n=4)$ samples. The normalized expression values are represented in shades of red and blue, indicating expression above and below the median expression value across all of the samples. (B) Relative expression of miR-30a-5p between ccRCCs $(n=249)$ and normal renal tissue samples ( $n=71$ ) (TCGA). (C) The up-regulated miR-30a-5p expression in ccRCC tissues was confirmed by qRT-PCR. (D) The expression of miR-30a-5p in the indicated RCC cell lines. (E) Relative expression of miR-30a-5p between TNM Stage I + II and III+IV tissue samples (TCGA). (F) Kaplan-Meier survival curve of ccRCC patients (TCGA) based on the levels of miR-30a-5p expression. "miR-30a-5p low" $(n=33)$ represents the bottom samples of the cases, whereas "miR-30a-5p high" $(n=209)$ is designated the top of the samples. A log-rank test was used to assess statistical significance. A similar classification was used for performing survival analysis based on the levels of miR-30a-5p. The results are presented as the mean $\pm \mathrm{SD}$. *, $\mathrm{P}<0.05 ; * *, \mathrm{P}<0.01 ; * * *, \mathrm{P}<0.001$.

correlated with the higher clinical grading of cancer tissues (Fig. 1E). Low expression of miR$30 a-5 p$ was associated with high TNM Stage $(P=0.001)$ and advanced pathological grade $(\mathrm{P}=0.046)$ of ccRCC patients (Table 2$)$. Kaplan-Meier survival analysis demonstrated that 


\section{Cellular Physiology Cell Physiol Biochem 2017;43:2405-2419

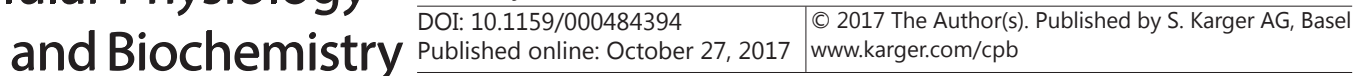 \\ Wang et al.: MicroRNA-30a-5p Inhibits the Growth of Renal Cell Carcinoma}

Table 2. Correlation between clinicopathological characteristics and miR-30a-5p expression levels in ccRCC patients

\begin{tabular}{|c|c|c|c|c|c|}
\hline \multirow[t]{2}{*}{ Characteristics } & \multirow[t]{2}{*}{ Number of patients } & \multicolumn{2}{|c|}{ miR-30a-5p } & \multirow[t]{2}{*}{$\chi^{2}$} & \multirow[t]{2}{*}{$\mathrm{P}$} \\
\hline & & $\begin{array}{c}\text { High expression } \\
(\%)\end{array}$ & $\begin{array}{c}\text { Low expression } \\
(\%)\end{array}$ & & \\
\hline Gender & & & & 1.415 & 0.234 \\
\hline Male & 83 & $75(34.7)$ & $8(24.2)$ & & \\
\hline Female & 166 & $141(65.3)$ & $25(75.8)$ & & \\
\hline Age & & & & 2.701 & 0.1 \\
\hline$\leq 65$ & 167 & $149(69.0)$ & $18(54.5)$ & & \\
\hline$>65$ & 82 & $67(31.0)$ & $15(45.5)$ & & \\
\hline TNM Stage & & & & 16.383 & 0.001 \\
\hline I & 131 & $118(54.6)$ & $13(39.4)$ & & \\
\hline II & 31 & $26(12.0)$ & $5(15.2)$ & & \\
\hline III & 81 & $70(32.4)$ & $11(33.3)$ & & \\
\hline IV & 6 & $2(1.0)$ & $4(12.1)$ & & \\
\hline Grade & & & & 7.987 & 0.046 \\
\hline Grade 1 & 9 & $9(4.2)$ & $0(0.0)$ & & \\
\hline Grade 2 & 96 & $88(41.1)$ & $8(24.2)$ & & \\
\hline Grade 3 & 101 & $86(40.2)$ & $15(45.5)$ & & \\
\hline Grade 4 & 41 & $31(14.5)$ & $10(30.3)$ & & \\
\hline Lymph node metastasis & & & & 0.014 & 0.906 \\
\hline No & 100 & $86(92.5)$ & $14(93.3)$ & & \\
\hline Yes & 8 & $7(7.5)$ & $1(6.7)$ & & \\
\hline
\end{tabular}

Table 3. Univariate and multivariate regression analyses of parameters associated with prognosis of ccRCC patients

\begin{tabular}{|c|c|c|c|c|c|}
\hline \multirow{2}{*}{ Characteristics } & \multirow{2}{*}{ Subset } & \multicolumn{2}{|c|}{ Univariate analysis } & \multicolumn{2}{|c|}{ Multivariate analysis } \\
\hline & & $\begin{array}{c}\text { Hazard ratio } \\
(95 \% \mathrm{CI})\end{array}$ & $P$ & $\begin{array}{c}\text { Hazard ratio } \\
(95 \% \mathrm{CI})\end{array}$ & $P$ \\
\hline Gender & Male/Female & $\begin{array}{c}0.996(0.594- \\
1.668)\end{array}$ & 0.987 & - & - \\
\hline Age & $\leq 65 />65$ & $1.52(0.939-2.461)$ & 0.088 & - & - \\
\hline Tumor Stage & $\mathrm{I}+\mathrm{II} / \mathrm{III}+\mathrm{IV}$ & $\begin{array}{c}1.897(1.476- \\
2.438)\end{array}$ & $<0.001$ & $\begin{array}{c}1.824(1.404- \\
2.37)\end{array}$ & $<0.001$ \\
\hline Tumor Grade & Grade(1+2)/Grade(3+4) & $\begin{array}{c}1.655(1.223- \\
2.239)\end{array}$ & 0.001 & $\begin{array}{c}2.042(1.097- \\
3.801)\end{array}$ & 0.024 \\
\hline $\begin{array}{l}\text { Lymph node } \\
\text { metastasis }\end{array}$ & Yes/No & $\begin{array}{c}5.759(2.169- \\
15.293)\end{array}$ & $<0.001$ & - & - \\
\hline miR-30a-5p & High/Low & $\begin{array}{c}0.549(0.304- \\
0.993)\end{array}$ & 0.047 & $\begin{array}{c}0.517(0.271- \\
0.984)\end{array}$ & 0.045 \\
\hline
\end{tabular}

patients with lowermiR-30a-5p expression had a shorter overall survival time compared ones with high miR-30a-5p expression (Fig. $1 \mathrm{~F}, \mathrm{P}=0.0441$ ). Univariate and multivariate Cox proportional hazards analyses showed that miR-30a-5p, as well as TNM stage and pathological grade, were identified to be independent prognostic factors for survival in ccRCC patients (Table 3 ). These results suggest that miR-30a-5pmight play a critical role in suppressing ccRCC.

MiR-30a-5p inhibits the proliferation and promotes apoptosis of ccRCC cells in vitro

To explore the anti-ccRCC role of miR-30a-5p, we performed gain- and loss-of-function experiments through transfection with agomiR-30a-5p and antagomiR-30a-5p. 786-0 and OS-RC-2 cells were transfected with inhibitor targeting miR-30a-5p (miR-30a-5p inhibitor) or a negative control (NC). The efficiency of miR-30a-5p knockdown by miR-30a-5p inhibitor was confirmed by quantifying the transcriptional levels of miR-30a-5p with qRT-PCR. As shown in Fig. 2A, the miR-30a-5p expression in 786-0 and OS-RC-2 cells was knocked down more than $70 \%$. The reduced expression of miR-30a-5p enhanced the proliferation of 7860 and OS-RC- 2 cells compared with the control cells transfected with miR-30a-5p NC (Fig. 


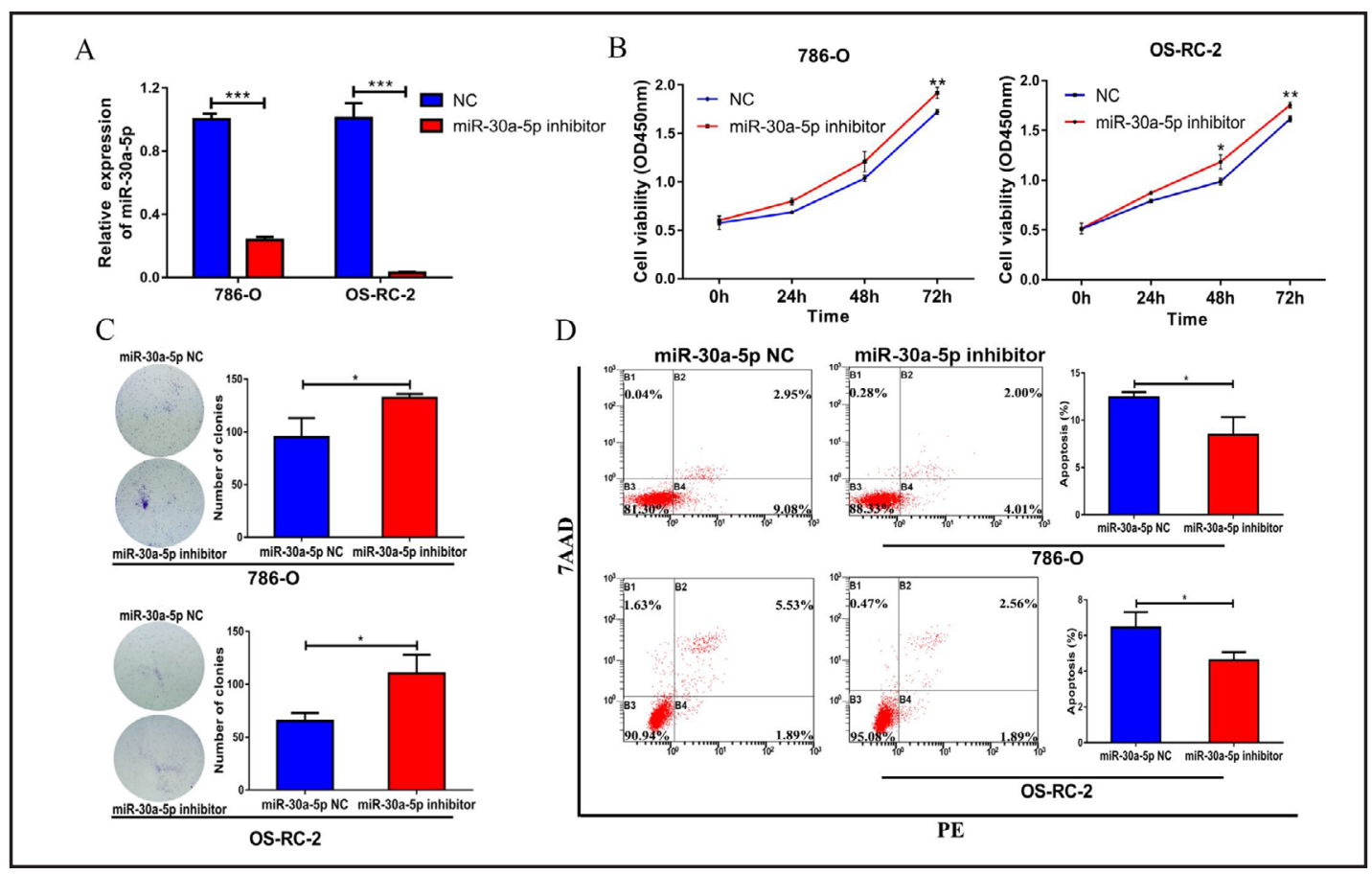

Fig. 2. Modulation of miR-30a-5p expression affects tumor growth. (A) Knockdown of miR-30a-5p expression in 786-0 and OS-RC-2 cells by transfecting miR-30a-5p inhibitor was confirmed by qRT-PCR. Suppression of miR-30a-5p expression resulted in increasing cellular growth (B) and colony formation (C), and inhibition of apoptosis (D) in 786-0 and OS-RC-2 cell lines. The results are presented as the mean \pm SD $(\mathrm{n}=3) .{ }^{*}, \mathrm{P}<0.05 ; * *, \mathrm{P}<0.01 ; * * *, \mathrm{P}<0.001$.

2B). The RCC suppressing role of miR-30a-5p was confirmed by the results of the clonogenic assay showing that knockdown of miR-30a-5p increased colony numbers in both RCC cell lines (Fig. 2C). In addition, miR-30a-5p knockdown resulted in decreased apoptosis in both 786-O and OS-RC-2 cells compared with mimic, B2 (PE Annexin V positive representing the cells in early apoptosis) and B4 (PE Annexin V and 7-AAD double positive representing the cells in late apoptosis) regions in the plot are accounted as the apoptotic cells (Fig. 2D). These results demonstrate that miR-30a-5p inhibits proliferation and promotes apoptosis of ccRCC cells in vitro.

\section{GRP78 is a direct target gene of miR-30a-5p}

MiRNAs execute various important functions primarily via servicing as key posttranscriptional modulators of gene expression. To explore the underlying mechanisms of miR-30a-5p in suppressing ccRCC, starBase v2.0 (http://starbase.sysu.edu.cn/) were applied to examine the potential major targets of miR-30a-5p. Analyses showed that miR-30a-5p targets GRP78 through a conserved binding site in the 3'-UTR of GRP78 (Fig. 3A). To confirm that GRP78 is the direct target gene of miR-30a-5p, two luciferase reporter plasmids were constructed with the wild type or mutant3'UTR of GRP78 cloned into the 3 'end of the luciferase gene (Fig. 3A). MiR-30a-5p significantly decreased the luciferase activity of the wild-type (WT) but not the Mut 3'-UTR of GRP78 in HEK293T cells (Fig. 3B). To further confirm that miR-30a-5p down-regulates GRP78 expression in ccRCC, we compared miR-30a-5p expression and GRP78 expression in TCGA database and found that GRP78 transcriptional expression was inversely correlated with miR-30a-5p expression in ccRCC $\left(r^{2}=0.07, P<0.0001\right.$, Fig. 3C). Next, we explored whether mRNA and protein expression of GRP78 in RCC cells is modulated by miR-30-5p in vitro. We first set up a cellular model of ER stress in ccRCC cells (786-0 or OS-RC-2) with thapsigargin (TG) for $12 \mathrm{~h}$. The overexpression of miR-30a-5pdecreased both the mRNA and protein levels of GRP78 in both ccRCC cells and 


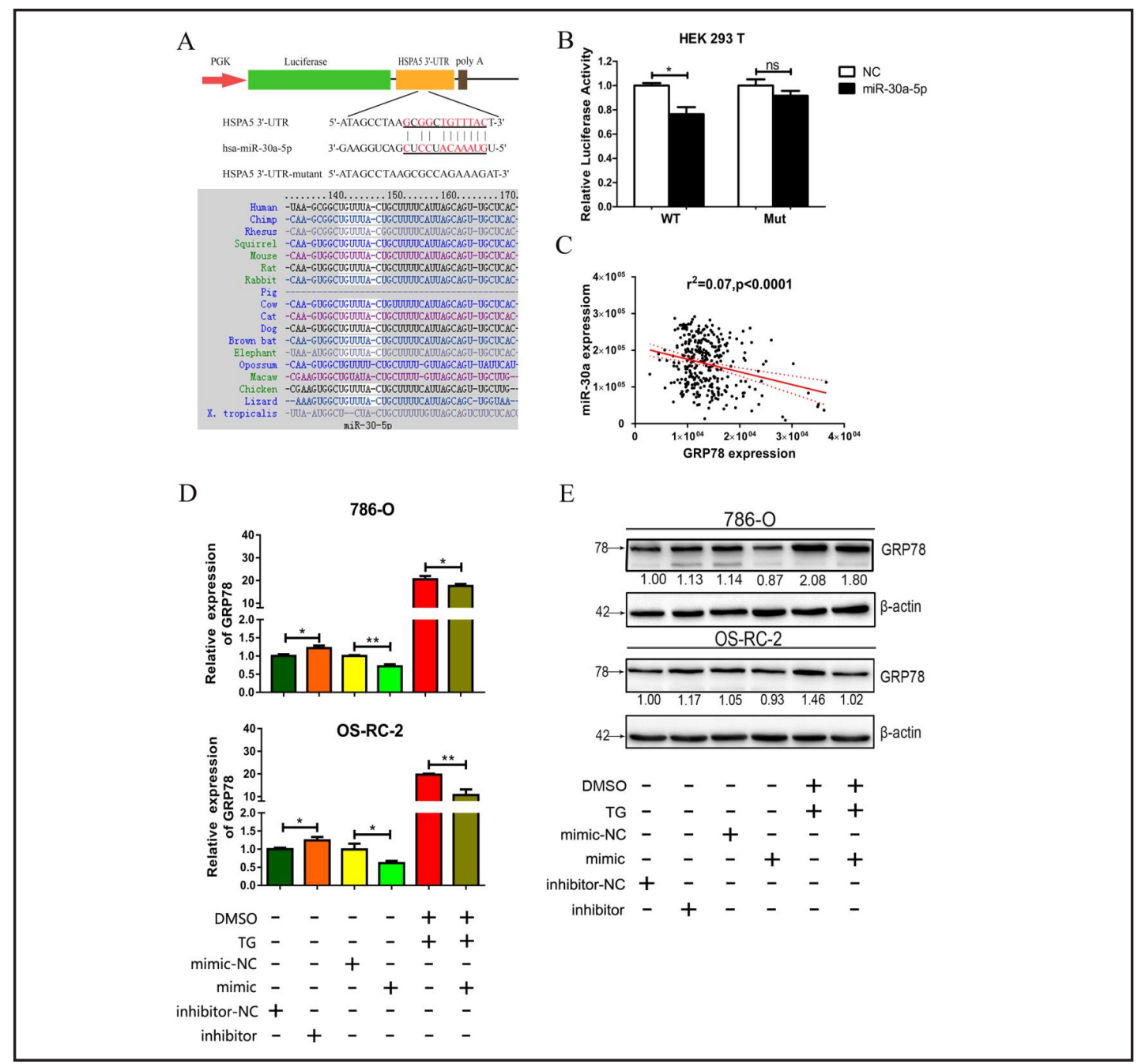

Fig. 3. MiR-30a-5p directly targets GRP78 gene and down-regulates GRP78 expression in ccRCC. (A) Schematic diagram of the predicted target binding sites of miR-30a-5p in the GRP78 3'-UTR. The seed recognition site is denoted. All nucleotides of the GRP78 3'-UTR region that binds with miR-30a-5p are highly conserved across species as predicated by TargetScan (http://www.targetscan.org/vert_71/). The predicted sites of miR-30a-5p are underlined and mutated as indicated. (B) The luciferase activity of the wild type GRP78 3'-UTR (WT) and mutant GRP78 3'-UTR (Mut) co-transfected with miR-30a-5p mimics or a miRNA negative control (NC) was measured. (C) Correlation between miR-30a-5p and GRP78 expression in ccRCCs (TCGA, $n=317$ ). (D) GRP78 mRNA expression was detected in ccRCC cells by qRT-PCR following transfection with miR-30a-5p mimics, miR-30a-5p inhibitor, or their negative controls. (E) Effects of miR30a-5p on GRP78 protein level measured by western blot analysis. Note that transfection of miR-30a-5p inhibitor to cells in the absence of TG up-regulated GRP78, indicating suppression of GRP78 under basal conditions. Transfection of miR-30a-5p mimics down-regulating TG-induced GRP78 overexpression. *, P< $0.05 ; * *, \mathrm{P}<0.01 ; * *, \mathrm{P}<0.001$.

TG treated ccRCC cells, and the knockdown of miR-30a-5p increased both the mRNA and protein levels of GRP78 in ccRCC cells with or without TG treatment (Fig. 3D and 3E). The results indicate that GRP78 is a direct target gene of miR-30a-5p and down-regulated by miR-30a-5p in ccRCC.

Anti-ccRCC functions of miR-30a-5p are mediated by suppressing GRP78 expression

GRP78, a marker of ER stress, has been reported to be up-regulated in RCC and to be involved in the growth of RENCA renal carcinoma cells $[23,24,30]$. To explore whether KARGER 
Fig. 4. GRP78 is aberrantly up-regulated in ccRCC tissues and associated with ccRCC prognosis. (A) Comparison of GRP78 expression between ccRCCs and normal renal tissue samples (TCGA). (B)Comparison of GRP78 expression between histological grade $1+2$ and $3+4$ tissue samples (TCGA). (C) Comparison of GRP78 expression between TNM Stage I + II and III+IV tissue samples (TCGA). (D) Kaplan-Meier survival curve based on the levels of GRP78 expression in patients with ccRCC (TCGA). "GRP78 low" ( $n=175)$ represents the bottom of the cases, whereas "GRP78 high" ( $\mathrm{n}=313)$ is designated the top of the samples. (E) Representative photomicrograph of immunohistochemical staining of GRP78 in ccRCC tissues. GRP78 expression occurs preferentially in ccRCC late tumor stage samples. Photographs were taken
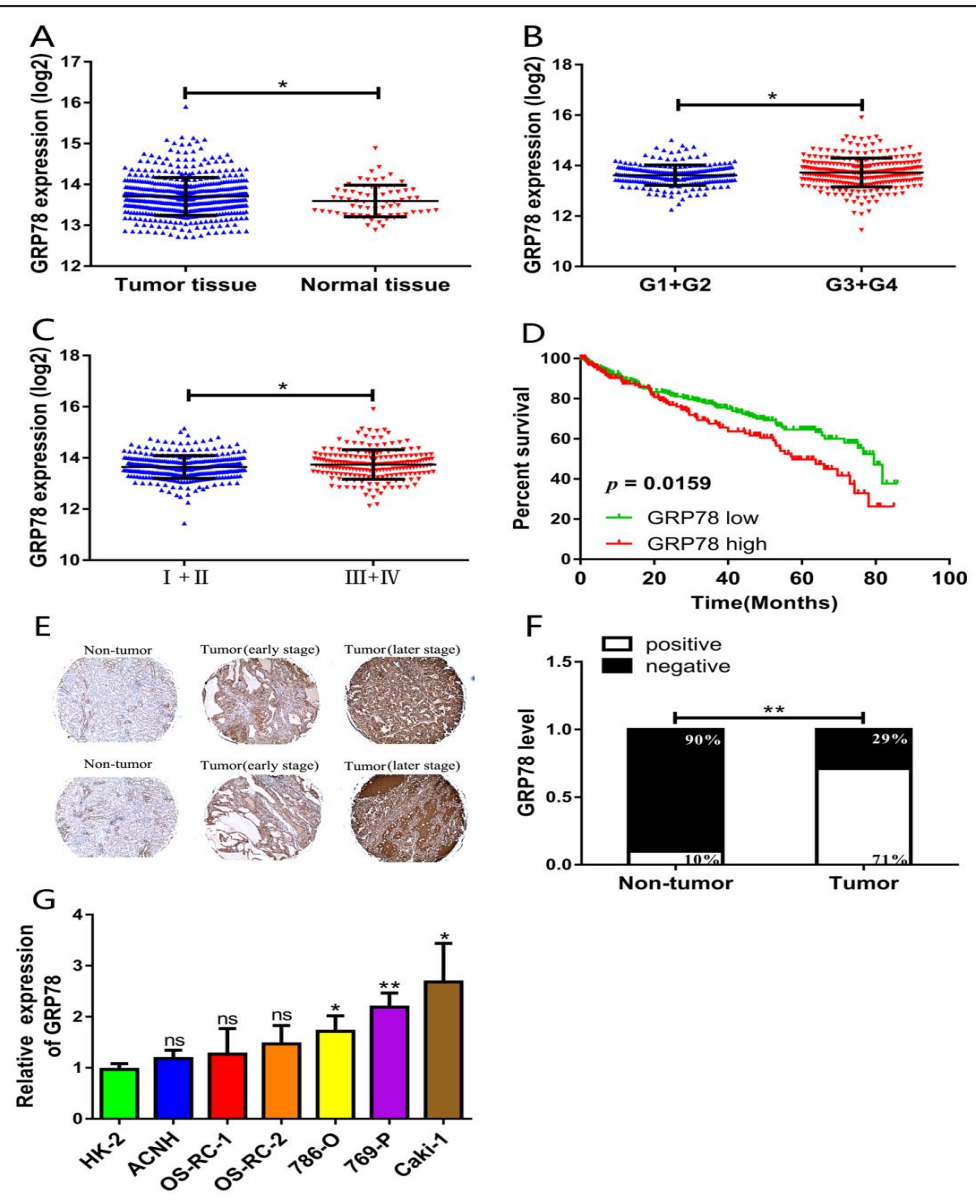

at $200 \times$ magnification. (F) The

levels of GRP78 expression in tumor or non-tumor tissues were analyzed by immunohistochemistry assays. (G) The expression of GRP78 in the indicated RCC cell lines quantified by qRT-PCR. * $\mathrm{P}<0.05$; ${ }^{* *}, \mathrm{P}<0.01$; ***, $\mathrm{P}<0.001$.

the anti-tumor function of miR-30a-5p in ccRCC is mediated by modulating the expression of GRP78, we initially analyzed the GRP78 expression pattern in ccRCC tissues and RCC cell lines. ccRCC samples in TCGA were analyzed and the results revealed that GRP78 is expressed at higher levels in ccRCC $(n=520)$ than in normal tissue samples $(n=72$, Fig. 4A). Meanwhile, higher levels of GRP78 expression were correlated with a higher TNM stage of cancer tissues (Fig. 4B and 4C). Kaplan-Meier survival analysis demonstrated that patients with high GRP78 expression had a shorter overall survival time compared to those with low GRP78 expression (Fig. 4D, $P=0.0159$ ). To further confirm this result, a tissue microarray containing 86 ccRCCs and 10 normal tissues was assayed for further validation. Using immunohistochemical staining, we confirmed that the endogenous expression of GRP78was positively correlated with tumor histological grade; the highest levels of GRP78 expression were observed in grade IV ccRCC samples (Fig. 4E). Moreover, increased expression of GRP78 was observed in ccRCC tissue microarray (Fig. 4F) and in 6 RCC cell lines (Fig. 4G). These results show that GRP78 is up-regulated in ccRCC and potentially plays a critical role in the pathogenesis of ccRCC.

To further study whether GRP78 regulates cancer cell growth, GRP78 was knocked down in 786-0 and OS-RC-2 cells with two siRNAs. Knockdown efficiency was confirmed by qRTPCR and Western blotting (Fig. 5A and 5B). Knockdown of GRP78 inhibited cellular growth (Fig. 5C). The suppression of RCC cell proliferation caused by knockdown of GRP78 was confirmed by counting colony numbers in both ccRCC cell lines in a colony formation assay 


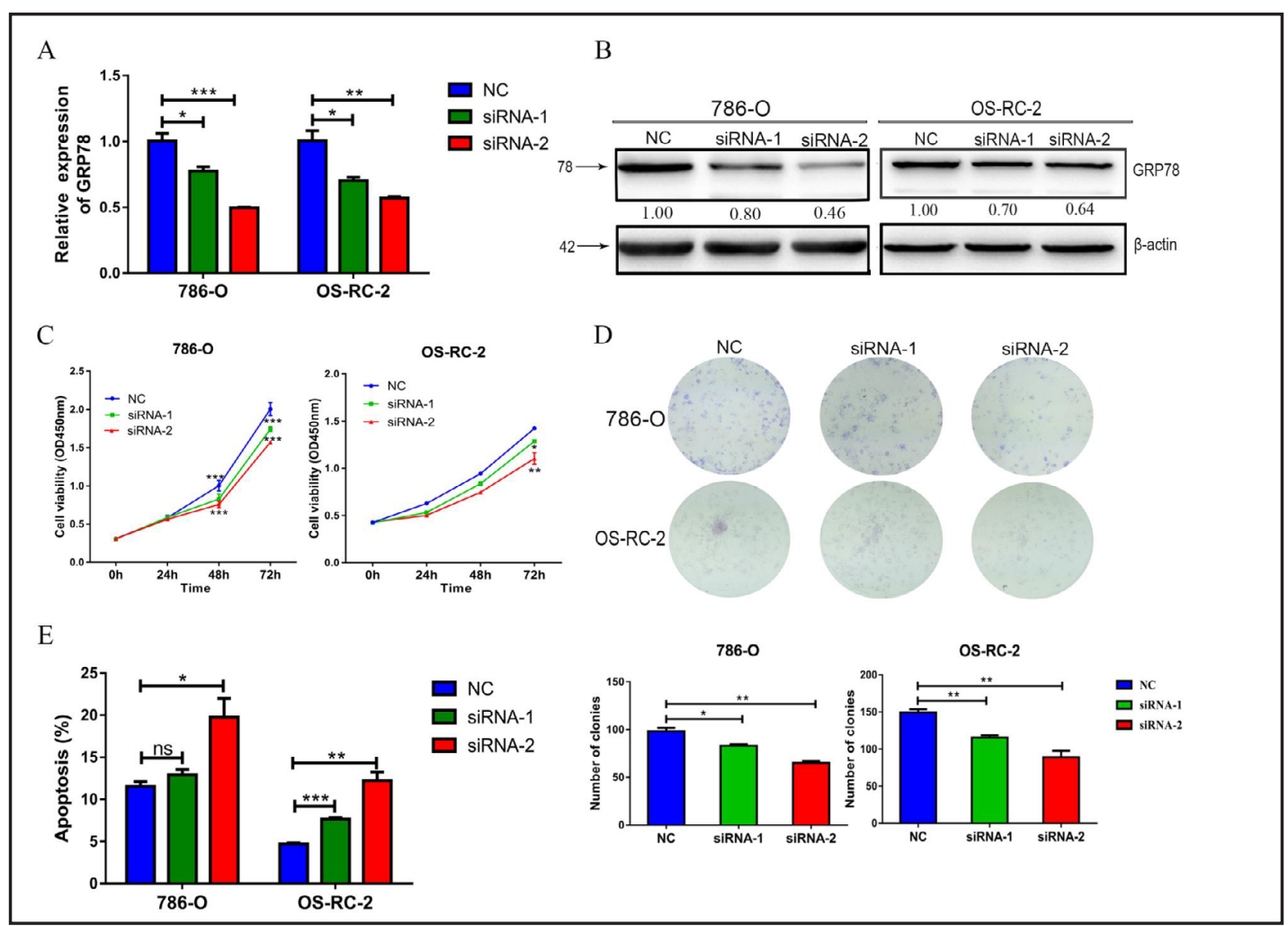

Fig. 5. The up-regulation of GRP78 expression promotes cellular growth and inhibits apoptosis. (A) Validation of ectopic knockdown of GRP78 by qRT-PCR in 786-0 and OS-RC-2 cell with two siRNAs. (B) The knockdown efficiency of GRP78 siRNA (siRNA-1, siRNA-2) in RCC cells was confirmed by Western blotting. $\beta$-actin was used as a loading control. Ectopic knockdown of GRP78expressioninhibited cellular proliferation (C), decreased the number of colonies formed (D), and promoted apoptosis (E) in 786-0 and OS-RC-2 cell lines. *, $\mathrm{P}<0.05 ;{ }^{* *}, \mathrm{P}<0.01 ;{ }^{* *}, \mathrm{P}<0.001$.

(Fig. 5D). Apoptosis was increased in ccRCC cells with knockdown of GRP78 as observed by flow cytometry analysis (Fig. 5E).

We demonstrated that GRP78 is a direct target gene of miR-30a-5p and that both miR-30a-5p overexpression and GRP78 knockdown suppresses ccRCC (Fig. 3-5). We next investigated whether the anti-tumor function of miR-30-5p is mediated through regulation of the expression of GRP78 in ccRCC. First, we transduced agomiR-30a-5p or negative control (NC) and overexpressed GRP78 plasmids. We found that overexpression of miR-30a-5p reduced GRP78 protein expression, while co-transfection of GRP78 overexpression plasmids could significantly rescue down-regulated GRP78 expression by miR30a-5p, though less than negative control (Fig. 6A and 6B). This indicates that miR-30a-5p reduces the GRP78 expression very efficiently. Co-transfection of GRP78 plasmid abrogated the suppressive effects of miR-30a-5p overexpression on the cellular proliferation of ccRCC 786-0 and OR-SC-2 cells (Fig. 6C and 6D). Meanwhile, co-transfection of GRP78 plasmid abolished the apoptosis enhanced by miR30a-5p overexpression (Fig. 6E). All these suggest that the suppressive effect of miR-30a-5pon ccRCC is mediated by decreasing GRP78 expression.

\section{Discussion}

MiRNAs are a class of non-coding small RNAs and have also been widely reported to be involved in a variety of tumorigenic processes. MiR-30a is one of the well- characterized miRNAs in cancers, and it exhibits diverse functions depending on the cancer type. Here, we 


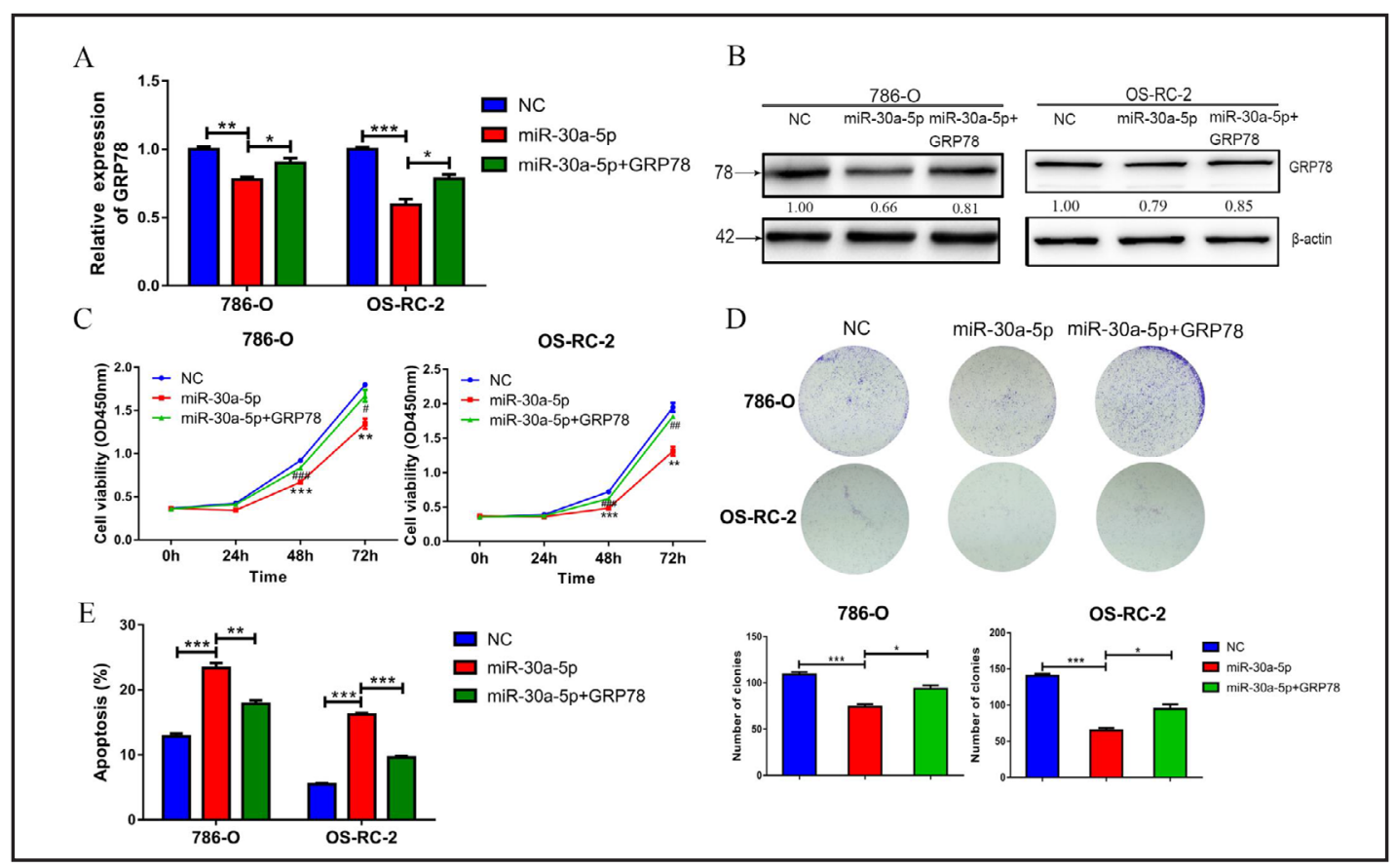

Fig. 6. MiR-30a-5p overexpression abolishes the pro-tumor activity of GRP78.(A) Expression levels of GRP78 as determined by qRT-PCR in 786-O and OS-RC-2 cells after transfection with negative control (NC), miR-30a-5p mimics and miR-30a-5p mimic+GRP78. (B) Western blot analysis of GRP78 after transfection cells with NC, miR-30a-5p mimics and miR-30a-5p mimic+GRP78. $\beta$-actin was used as a loading control. (C, D) GRP78 overexpression reverted the suppressive effects of miR-30a-5p overexpression on the cell growth rate and colony formation of 786-0 and OS-RC-2 cell lines. (E) GRP78 overexpression reversed the miR-30a$5 \mathrm{p}$ induced promotion of apoptosis of 786-0 and OS-RC-2 cell lines. ${ }^{*}, \mathrm{P}<0.05 ;{ }^{* *}, \mathrm{P}<0.01 ; * * *, \mathrm{P}<0.001$.

found that within the miR-30 family, only miR-30a-5p was found to exhibit significant variation between ccRCC and normal renal cells (Fig. 1A and Table 4). MiR-30a$5 p$ was down-regulated in ccRCC tissues and was closely correlated with advanced TNM stage and poorer overall survival. MiR-30a-5p levels are negatively associated with ccRCC prognosis and miR-30a-5p suppresses the cell growth of ccRCC, which is mediated by modulating the expression of its direct target gene GRP78. These results suggest that miR-30a-5p might function as a tumor suppressor in ccRCC.

It is well established that miRNAs as a key modulator of protein expression are dysregulated in tumors and are closely involved in carcinogenesis. MiR-30a-5p has demonstrated to play crucial role in suppressing cancer prognosis in several cancers including glioma, breast cancer, Colorectal Cancer. In this study, we demonstrated that miR-30a-5p was repressed in ccRCC in vivo and in vitro. Consistent with our results, in a recent elegant study, Chen et al. shows that miR-30a-5p expression is restricted and the reduced expression of mir-30a-5p promotes ccRCC prognosis [31]. Von Hippel-Lindau gene (VHL) has been reported as a tumor-suppressor gene, which is associated with ccRCC $[32,33]$. Mathew et al. has found that miR-30a-3p is repressed in the VHL deficient ccRCC tumors [34]. But why miR-30a-5p expression was decreased in ccRCC is still completely unclear. Chen et al. demonstrates that the miR-30a-5p expression is regulated by long noncoding RNA (lncRNA) DLEU2 in ccRCC [31]. Previous study also
Table 4. Comparison of miR-30 family members between ccRCC and adjacent normal tissue

\begin{tabular}{lcc}
\hline miRNA & Log FC & P \\
\hline hsa-miR-30a-5p & 1.4108 & 0.0165 \\
hsa-miR-30b-3p & 0.9376 & 0.0182 \\
hsa-miR-30d-5p & 0.8578 & 0.0218 \\
hsa-miR-30c-2-3p & 1.1529 & 0.0325 \\
hsa-miR-30c-5p & 1.0464 & 0.0387 \\
hsa-miR-30a-3p & 1.5337 & 0.0414 \\
hsa-miR-30e-5p & 0.5231 & 0.0602 \\
hsa-miR-30e-3p & 1.0027 & 0.0746 \\
hsa-miR-30d-3p & 0.7753 & 0.2934 \\
hsa-miR-30b-5p & 0.3922 & 0.3134 \\
hsa-miR-30c-1-3p & 0.2754 & 0.4527 \\
\hline
\end{tabular}




\section{Cellular Physiology Cell Physiol Biochem 2017;43:2405-2419

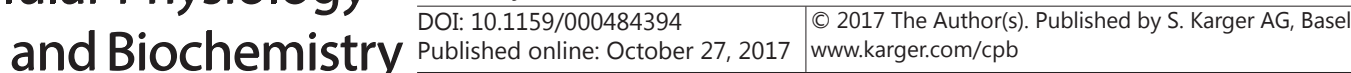 \\ Wang et al.: MicroRNA-30a-5p Inhibits the Growth of Renal Cell Carcinoma}

Fig. 7. Schematic illustration of the proposed miR30a-5p /GRP78 signaling pathway and the regulatory mechanisms between miR-30 and GRP78. MiR-30a$5 p$ targeting the GRP78 gene and down-regulating GRP78 expression is suppressed in ccRCC. The upregulated expression of GRP78 in ccRCC alleviates stress, promotes cell proliferation and exerts protumor activity. Thus, the miR-30-GRP78 interaction provides a novel therapeutic for ccRCC patients.

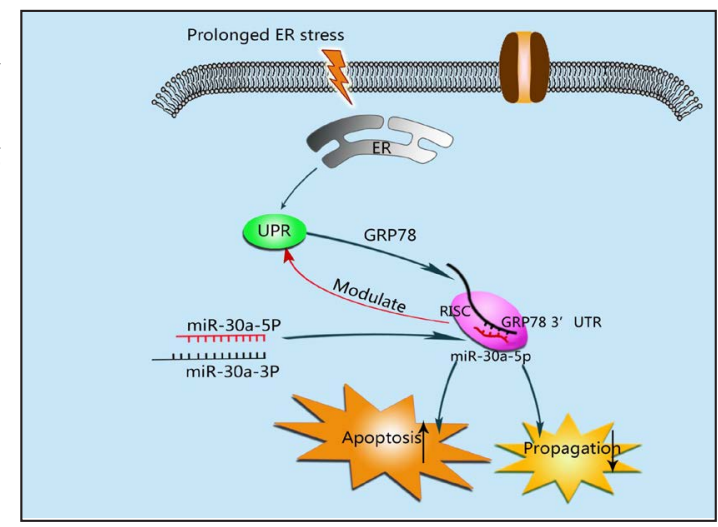

demonstrates that miR-30a expression could be also regulated by the protein encoded by VHL [34]. It is worthwhile to further study the mechanism of the restricted expression of the putative tumor suppressor miR-30a-5p in ccRCC.

GRP78 is an important biomarker of ER stress and is regarded as the master regulator of the UPR pathway. Much evidence has demonstrated that GRP78, an ER chaperone, exerts a pro-survival role for different tumor cells and is correlated with higher tumor grade, advanced tumor stage, distant metastases, and shorter survival [35-37]. Consistent with the studies from other groups, we also showed that the up-regulation of GRP78 expression is observed in ccRCC. The increased expression of GRP78 is correlated with ccRCC grade, advanced stage, and shorter survival of ccRCC patients, RCC tumor proliferation, tumor antiapoptosis. However, the underlying mechanism of the increased GRP78 expression in ccRCC is still elusive. One mechanism is ER stress caused by the synthesis of a significant quantity of new proteins required by neoplastic growth. Here we presented another mechanism that miR-30a-5p expression is down-regulates in ccRCC, which boosts GRP78 expression in ccRCC. This is consistent with the previous study that GRP78 expression modulated by miR-30a is found in the cardiovascular system in response to ER stress [27]. We found that miR-30a-5p could directly target GRP78 3'-UTR, and miR-30a-5p directly suppresses GRP78 expression in ccRCC tissue in vivo and ccRCC cells in vitro. Thus, the miR-30-GRP78 interaction provides a novel therapeutic target for ccRCC.

\section{Conclusion}

In summary, our study demonstrated that miR-30a-5p is down-regulated in ccRCC and possesses anti-tumor effects on ccRCC through its target gene GRP78 (Fig. 7). Overexpression of GRP78 is correlated with the development of ccRCC and promotes multiple malignant biological behaviors, including the promotion of tumor cell growth and anti-apoptosis. Down-regulation of GRP78 by miR-30a-5p could abolish malignant biological behavior changes induced by the increased expression of GRP78 in ccRCC. In conclusion, our findings indicate that miR-30a-5p acts as a putative tumor suppressor in ccRCC. The miR-30-GRP78 interaction could be used as a novel target for ccRCC early diagnosis and therapy.

\section{Abbreviations}

3'UTR (3'-untranslatedregion); RCC (renal cell carcinoma); ccRCC (clear cell renal cell carcinoma); GEO (Gene expression omnibus); TCGA (the Cancer Genome Atlas); UPR (unfolded protein response); GRP78 (glucose-regulated protein 78); BiP (binding protein); HSPA5 (heat shock protein family A member 5); IncRNA (long noncoding RNA); VHL (von Hippel-Lindau). 


\section{Cellular Physiology Cell Physiol Biochem 2017;43:2405-2419 and Biochemistry \begin{tabular}{c|c|c|} 
DOI: 101159/000484394 \\
Published online: October 27, 2017 & $\begin{array}{l}\text { O } 2017 \text { The Author(s). Published by S. Karger AG, Basel } \\
\text { www.karger.com/cpb }\end{array}$
\end{tabular} \\ Wang et al.: MicroRNA-30a-5p Inhibits the Growth of Renal Cell Carcinoma}

\section{Acknowledgements}

The present study was funded by the National Natural Science Foundation of China [grant numbers 81171996 and 81272289 to Cheng Zhang], the Wujieping Medical Foundation [grant number 320.6750.13252 to Cheng Zhang].

\section{Disclosure Statement}

The authors declare no conflict of interest.

\section{References}

1 Jemal A, Bray F, Center MM, Ferlay J, Ward E, Forman D: Global cancer statistics. CA Cancer J Clin 2011;61:69-90.

2 Meloni-Ehrig AM: Renal cancer: cytogenetic and molecular genetic aspects. Am J Med Genet 2002;115:164172.

- 3 Youssef YM, White NM, Grigull J, Krizova A, Samy C, Mejia-Guerrero S, Evans A, Yousef GM: Accurate molecular classification of kidney cancer subtypes using microRNA signature. Eur Urol 2011;59:721-730.

4 Ma W, Tao L, Wang X, Liu Q, Zhang W, Li Q He C, Xue D, Zhang J, Liu C: Sorafenib Inhibits Renal Fibrosis Induced by Unilateral Ureteral Obstruction via Inhibition of Macrophage Infiltration. Cell Physiol Biochem 2016;39:1837-1849.

5 Tian X, Dai S, Sun J, Jiang S, Sui C, Meng F, Li Y, Fu L, Jiang T, Wang Y, Su J, Jiang Y: Inhibition of MDM2 Re-Sensitizes Rapamycin Resistant Renal Cancer Cells via the Activation of p53. Cell Physiol Biochem 2016;39:2088-2098.

6 Novara G, Ficarra V, Antonelli A, Artibani W, Bertini R, Carini M, Cosciani Cunico S, Imbimbo C, Longo N, Martignoni G, Martorana G, Minervini A, Mirone V, Montorsi F, Schiavina R, Simeone C, Serni S, Simonato A, Siracusano S, Volpe A, Carmignani G, Foundation SP-L: Validation of the 2009 TNM version in a large multiinstitutional cohort of patients treated for renal cell carcinoma: are further improvements needed? Eur Urol 2010;58:588-595.

7 Cohen HT, McGovern FJ: Renal-cell carcinoma. N Engl J Med 2005;353:2477-2490.

-8 Bartel DP: MicroRNAs: genomics, biogenesis, mechanism, and function. Cell 2004;116:281-297.

-9 Cullen BR: Transcription and processing of human microRNA precursors. Mol Cell 2004;16:861-865.

10 Aguda BD: Modeling microRNA-transcription factor networks in cancer. Adv Exp Med Biol 2013;774:149167.

11 Fritz HK, Lindgren D, Ljungberg B, Axelson H, Dahlback B: The miR(21/10b) ratio as a prognostic marker in clear cell renal cell carcinoma. Eur J Cancer 2014;50:1758-1765.

$\checkmark 12$ Kawakami K, Enokida H, Chiyomaru T, Tatarano S, Yoshino H, Kagara I, Gotanda T, Tachiwada T, Nishiyama K, Nohata N, Seki N, Nakagawa M: The functional significance of miR-1 and miR-133a in renal cell carcinoma. Eur J Cancer 2012;48:827-836.

13 Zhong M, Bian Z, Wu Z: miR-30a Suppresses Cell Migration and Invasion Through Downregulation of PIK3CD in Colorectal Carcinoma. Cell Physiol Biochem 2013;31:209-218.

14 Zhao JJ, Lin J, Zhu D, Wang X, Brooks D, Chen M, Chu ZB, Takada K, Ciccarelli B, Admin S, Tao J, Tai YT, Treon S, Pinkus G, Kuo WP, Hideshima T, Bouxsein M, Munshi N, Anderson K, Carrasco R: miR-30-5p functions as a tumor suppressor and novel therapeutic tool by targeting the oncogenic Wnt/beta-catenin/BCL9 pathway. Cancer Res 2014;74:1801-1813.

15 Tanic M, Yanowsky K, Rodriguez-Antona C, Andres R, Marquez-Rodas I, Osorio A, Benitez J, MartinezDelgado B: Deregulated miRNAs in hereditary breast cancer revealed a role for miR-30c in regulating KRAS oncogene. PLoS One 2012;7:e38847.

16 Wu C, Jin B, Chen L, Zhuo D, Zhang Z, Gong K, Mao Z: MiR-30d induces apoptosis and is regulated by the Akt/FOXO pathway in renal cell carcinoma. Cell Signal 2013;25:1212-1221.

-17 Li W, Liu C, Zhao C, Zhai L, Lv S: Downregulation of beta3 integrin by miR-30a-5p modulates cell adhesion and invasion by interrupting Erk/Ets1 network in triple-negative breast cancer. Int J Oncol 2016;48:11551164.

18 He R, Yang L, Lin X, Chen X, Lin X, Wei F, Liang X, Luo Y, Wu Y, Gan T, Dang Y, Chen G: MiR-30a-5p suppresses 


\section{Cellular Physiology Cell Physiol Biochem 2017;43:2405-2419

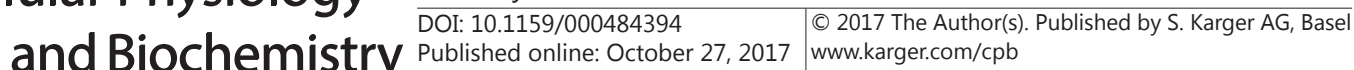

cell growth and enhances apoptosis of hepatocellular carcinoma cells via targeting AEG-1. Int J Clin Exp Pathol 2015;8:15632-15641.

19 Wang Z, Dai X, Chen Y, Sun C, Zhu Q, Zhao H, Liu G, Huang Q, Lan Q: MiR-30a-5p is induced by Wnt/betacatenin pathway and promotes glioma cell invasion by repressing NCAM. Biochem Biophys Res Commun 2015;465:374-380.

20 Baraniskin A, Birkenkamp-Demtroder K, Maghnouj A, Zollner H, Munding J, Klein-Scory S, Reinacher-Schick A, Schwarte-Waldhoff I, Schmiegel W, Hahn SA: MiR-30a-5p suppresses tumor growth in colon carcinoma by targeting DTL. Carcinogenesis 2012;33:732-739.

-21 Igci YZ, Ozkaya M, Korkmaz H, Bozgeyik E, Bayraktar R, Ulasli M, Erkilic S, Eraydin A, Oztuzcu S: Expression Levels of miR-30a-5p in Papillary Thyroid Carcinoma: A Comparison Between Serum and Fine Needle Aspiration Biopsy Samples. Genet Test Mol Biomarkers 2015;19:418-423.

22 Pfaffenbach KT, Lee AS: The critical role of GRP78 in physiologic and pathologic stress. Curr Opin Cell Biol 2011;23:150-156.

23 Fu W, Wu X, Li J, Mo Z, Yang Z, Huang W, Ding Q: Upregulation of GRP78 in renal cell carcinoma and its significance. Urology 2010;75:603-607.

24 Kuroda K, Horiguchi A, Asano T, Ito K, Asakuma J, Sato A, Yoshii H, Hayakawa M, Sumitomo M, Asano T: Glucose-regulated protein 78 positivity as a predictor of poor survival in patients with renal cell carcinoma. Urol Int 2011;87:450-456.

25 Lin JA, Fang SU, Su CL, Hsiao CJ, Chang CC, Lin YF, Cheng CW: Silencing glucose-regulated protein 78 induced renal cell carcinoma cell line G1 cell-cycle arrest and resistance to conventional chemotherapy. Urol Oncol 2014;32:29 e21-11.

26 Wang P, Zhang N, Liang J, Li J, Han S, Li J: Micro-RNA-30a regulates ischemia-induced cell death by targeting heat shock protein HSPA5 in primary cultured cortical neurons and mouse brain after stroke. J Neurosci Res 2015;93:1756-1768.

27 Chen M, Ma G, Yue Y, Wei Y, Li Q Tong Z, Zhang L, Miao G, Zhang J: Downregulation of the miR-30 family microRNAs contributes to endoplasmic reticulum stress in cardiac muscle and vascular smooth muscle cells. Int J Cardiol 2014;173:65-73.

28 Wei W, Yang Y, Cai J, Cui K, Li RX, Wang H, Shang X, Wei D: MiR-30a-5p Suppresses Tumor Metastasis of Human Colorectal Cancer by Targeting ITGB3. Cell Physiol Biochem 2016;39:1165-1176.

29 Chang CW, Yu JC, Hsieh YH, Yao CC, Chao JI, Chen PM, Hsieh HY, Hsiung CN, Chu HW, Shen CY, Cheng CW: MicroRNA-30a increases tight junction protein expression to suppress the epithelial-mesenchymal transition and metastasis by targeting Slug in breast cancer. Oncotarget 2016;7:16462-16478.

-30 Matsumura K, Sakai C, Kawakami S, Yamashita F, Hashida M: Inhibition of cancer cell growth by GRP78 siRNA lipoplex via activation of unfolded protein response. Biol Pharm Bull 2014;37:648-653.

-31 Chen Z, Zhang J, Zhang Z, Feng Z, Wei J, Lu J, Fang Y, Liang Y, Cen J, Pan Y, Huang Y, Zhou F, Chen W, Luo J: The putative tumor suppressor microRNA-30a-5p modulates clear cell renal cell carcinoma aggressiveness through repression of ZEB2. Cell Death Dis 2017;8:e2859.

-32 Yang L, Zhao Z, Zhao S, Chen C, Cong X, Li Z, Ren M: The Clinicopathological Significance of Epigenetic Silencing of VHL Promoter and Renal Cell Carcinoma: A Meta-Analysis. Cell Physiol Biochem 2016;40:14651472.

33 Luo F, Shi J, Shi Q Xu X, Xia Y, He X: Mitogen-Activated Protein Kinases and Hypoxic/Ischemic Nephropathy. Cell Physiol Biochem 2016;39:1051-1067.

-34 Mathew LK, Lee SS, Skuli N, Rao S, Keith B, Nathanson KL, Lal P, Simon MC: Restricted expression of miR30c-2-3p and miR-30a-3p in clear cell renal cell carcinomas enhances HIF2alpha activity. Cancer Discov 2014;4:53-60.

35 Chang YW, Tseng CF, Wang MY, Chang WC, Lee CC, Chen LT, Hung MC, Su JL: Deacetylation of HSPA5 by HDAC6 leads to GP78-mediated HSPA5 ubiquitination at K447 and suppresses metastasis of breast cancer. Oncogene 2016;35:1517-1528.

-36 Fang L, Gong J, Wang Y, Liu R, Li Z, Wang Z, Zhang Y, Zhang C, Song C, Yang A, Ting JP, Jin B, Chen L: MICA/B expression is inhibited by unfolded protein response and associated with poor prognosis in human hepatocellular carcinoma. J Exp Clin Cancer Res 2014;33:76.

-37 Li H, Song H, Luo J, Liang J, Zhao S, Su R: Knockdown of glucose-regulated protein 78 decreases the invasion, metalloproteinase expression and ECM degradation in hepatocellular carcinoma cells. J Exp Clin Cancer Res 2012;31:39. 